\title{
Protocol for the fast isolation and identification of insecticidal Bacillus thuringiensis strains from soil
}

Palma $\mathrm{L}^{1,2 \mathrm{I}}$

1.Facultad de Ciencias Agrarias, Universidad Nacional del Litoral, Esperanza, Santa Fe, Argentina

2.Consejo Nacional de Investigaciones Científicas y Técnicas, Argentina

\. Corresponding author email: 1palma@fca.unl.edu.ar

Bt Research, 2015, Vol.6, No.7 doi: 10.5376/bt.2015.06.0007

Received: 19 Aug., 2015

Accepted: 20 Sep., 2015

Published: 10 Oct., 2015

Copyright @ 2015 Palma et al., This is an open access article published under the terms of the Creative Commons Attribution License, which permits unrestricted use, distribution, and reproduction in any medium, provided the original work is properly cited.

Preferred citation for this article:

Palma L 2015, Protocol for the fast isolation and identification of insecticidal Bacillus thuringiensis strains from soil, Bt Research, Vol.6, No.7, 1-3 (doi: $\underline{10.5376 / \mathrm{bt} .2015 .06 .0007)}$

\begin{abstract}
Bacillus thuringiensis (Bt) is an ubiquitous, Gram-positive and sporulating bacterium that synthesizes insecticidal proteins with specificity against a wide range of insects during sporulation (Cry and Cyt) and vegetative growth (Vip and Sip). These proteins have portrayed $\mathrm{Bt}$ as an environment-friendly alternative to chemical insecticides. However, the intensive use of this resource has promoted the evolution of insect resistance to some of the most used Bt strains to date. Continuous efforts are needed to obtain novel strains exhibiting new specificities in order to overcome insect resistance and maintaining the insecticidal potential of this bacterium. In this work, an experimental procedure for the fast isolation and identification of insecticidal $\mathrm{Bt}$ strains is described.
\end{abstract}

Keywords Bacillus thuringiensis (Bt); Bt toxins; biological control

\section{Introduction}

Bacillus thuringiensis (Bt) is a Gram-positive and sporulated bacterium that synthesizes a number of invertebrate active toxins with specific activity against a wide range of insects (de Maagd et al., 2003; Schnepf et al., 1998; van Frankenhuyzen, 2009). The $\delta$-endotoxins, including Crystal (Cry) and cytolytic (Cyt) protein families are the best characterized group of insecticidal proteins and are synthesized during the stationary growth phase as crystalline parasporal inclusions (Schnepf et al., 1998; van Frankenhuyzen, 2009). In addition, Bt also produces other insecticidal proteins during the vegetative growth, the vegetative insecticidal proteins (Vips) and the secreted insecticidal protein (Sip), with toxicity against coleopteran (binary Vip1/Vip2 and Sip toxins) and lepidopteran (Vip3) pests (Donovan et al., 2006; Estruch et al., 1996; Warren et al., 1998). Strains producing these insecticidal proteins are commonly used in insecticidal formulations and their encoding genes, in the construction of transgenic plants (Sanchis, 2011), making the Bt-based products, the most marketed microbial pesticides worldwide (Roh et al., 2007; Schnepf et al., 1998). The broad diversity of insecticidal genes encoded by this bacterium strongly suggest that they resulted from high selective evolutionary pressures (de Maagd et al.,
2003; Wu et al., 2007a; Wu et al., 2007b), that led to the enlargement of their target ranges and made $\mathrm{Bt}$ a broad source of insecticidal proteins (Palma et al., 2014). On the other hand, insects targeted by Bt-based insecticides, also suffered from selective pressures and began to show symptoms of resistance to some of the most frequently used insecticidal strains and toxins (Ferré and Van Rie, 2002; Tabashnik et al., 2009). These emerging insect resistance events are threatening the efficiency of the most used Bt-based biopesticides and demand the searching of novel insecticidal strains exhibiting novel specificities and host ranges. This protocol specifies the experimental procedure for the fast isolation and identification of insecticidal $\mathrm{Bt}$ strains from soil. In this work, an experimental procedure for the fast isolation and identification of insecticidal Bt strains is described.

\section{Sampling}

In this protocol, soil samples were obtained with a tubular soil sampler and consisted of $\sim 20 \mathrm{~g}$ of cultivated or non-cultivated soil after removing the 2-3 $\mathrm{cm}$ of the top layer, to prevent low abundance levels of viable Bt spores due the effect of UV radiation from sun (Iriarte et al., 1998). After collection procedure, samples can be stored at $4{ }^{\circ} \mathrm{C}$ in 


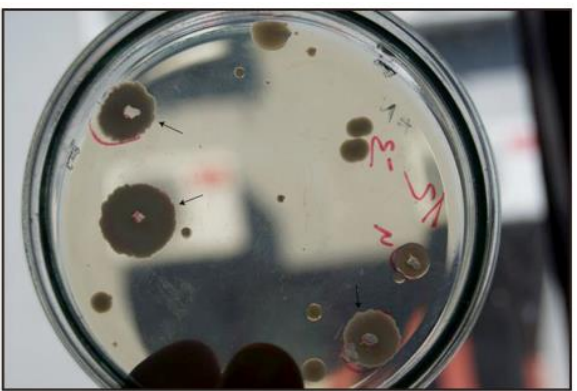

Figure 1 Isolated Bt-like colonies from soil samples (indicated by black arrows)

$50 \mathrm{ml}$ (sterile) centrifuge tubes or zip-lock bags until isolation.

\section{Isolation and identification}

Vegetative cells from sporulated bacteria (Figure 1) were isolated by homogenization of $3 \mathrm{~g}$ of each soil sample in $10 \mathrm{ml}$ of sterile distilled water, which was later mixed by intense vortexing for $1 \mathrm{~min}$. and incubated at $70{ }^{\circ} \mathrm{C}$ for $15 \mathrm{~min}$., after that, samples were vortexed and heated again as previously described. Each sample was then subjected to five ten-fold dilutions and $50 \mu \mathrm{l}$ (from $10^{-3}$ to $10^{-5}$ dilutions) were plated using a Drigalsk spatula onto Petri dishes containing nutrient agar ( $0.5 \%$ Peptone, $0.3 \%$ beef extract, $0.5 \% \mathrm{NaCl}$ and $1.5 \%$ agar). Plates were incubated at $28{ }^{\circ} \mathrm{C}$ for at least $72 \mathrm{~h}$. Bacterial colonies exhibiting Bt-like phenotype (matte white colour, flat, dry and uneven borders) (Figure 2) were sub-cultured for single-colony isolation with a $5 \mu$ inoculating loop and incubated as before. Each sporulated culture was then heat fixed and stained $(0,133 \%$ Coomassie Blue stain in $50 \%$ acetic acid) in a glass microscope slide (Ammons et al., 2002). The Bt-like cells identification was performed by microscopic examination using a Leyca DM 750 bright field microscope (Leyca Microsystems). Those colonies showing Coomassie Blue stained parasporal crystals were stored at $-20{ }^{\circ} \mathrm{C}$ in $50 \%$ glycerol

\section{Determining the insecticidal activity of} novel Bt isolates against Spodoptera cosmioides.

Preliminary bioassays (Figure 3) were performed by surface contamination of artificial diet for lepidopteran (1.3 $\mathrm{g}$ benzoic acid, $128,4 \mathrm{~g}$ corn grits, $32.1 \mathrm{~g}$ wheat germ, $34.3 \mathrm{~g}$ beer yeast, $4.5 \mathrm{~g}$ ascorbic acid, $1.1 \mathrm{~g}$ methylparaben (Nipagin), $0.5 \mathrm{~mL}$ formaldehyde, $12 \mathrm{~g}$ of Agar and $779.5 \mathrm{~mL}$ of distilled water), using first

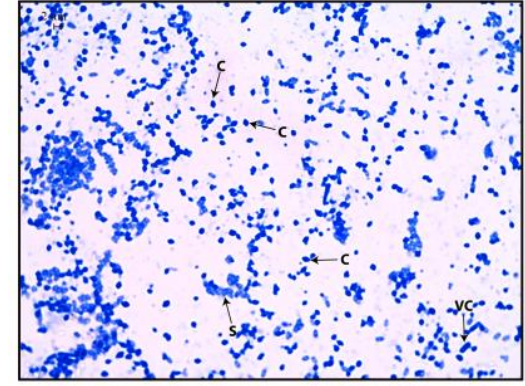

Figure 2 Sporulated Bt culture of Bacillus thuringiensis subsp. kurstaki HD1 strain showing rhomboidal parasporal crystals (C), spores (S) and vegetative cells (VC). In order to highlight parasporal crystals, the culture has been heat fixed and stained with Coomassie Blue (Ammons et al., 2002). Microphotograph (1000×) was obtained with a Leica DM750 microscope and its incorporated ICC50 digital camera (Leica Microsystems)

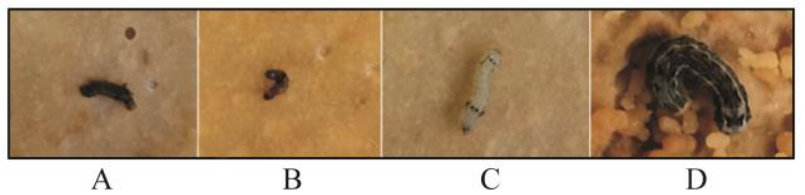

Figure 3. Preliminary bioassays results obtained with $S$. cosmioides larvae. (A) Dead $S$. cosmioides larvae treated with HD1 Bt strain; active against Lepidoptera (B) Dead $S$. cosmioides larvae treated with HD133 Bt strain, also active against Lepidoptera (C) S. cosmioides larvae exhibiting impaired growth when treated with IPS82 Bt strain, a strain active against Diptera (mosquitoes and black flies). (C) Negative control (sterile water)

instar Spodoptera cosmioides (Walker) larvae (Figure 3). Sporulated cultures of $\mathrm{Bt}$ isolates (mix of spores and crystals) were obtained from nutrient agar plates by scrapping the surface of agar with an inoculating loop. This material, corresponding to the entire Petri plate surface, was then diluted in $1 \mathrm{ml}$ of distilled water and homogeneizated by vortexing vigorously for $1 \mathrm{~min}$. at room temperature (RT). After mixing, $100 \mu \mathrm{l}$ were loaded onto the surface of the solid lepidopteran artificial diet, spread with a Drigalski spatula and allowed to dry at RT. Bioassays were conducted with neonate larvae that were placed onto the surface of contaminated artificial diet. Sterile water was used as a negative control and the commercial Bt strains HD1 (Bt subsp. kurstaki), HD133 (Bt subsp. aizawai) and IPS82 (Bt subsp. israelensis) were used as positive controls. Ten larvae were used for each plate and each bioassay was 
repeated twice. Bioassays were conducted at $28^{\circ} \mathrm{C} \pm$ $2^{\circ} \mathrm{C}$ and a 16: 8-h (light/dark) photoperiod. Absolute mortality and functional mortality rates (dead larvae plus larvae remaining in the first instar) were scored after 7 days.

\section{Notes}

By developing the experimental procedure described in this protocol, the Bt-like isolates can be preliminary identified as Bacillus thuringiensis in 5 days of work, from the isolation to the preliminary determination of its toxic activity. However, further studies such as PCR amplification and sequencing of $16 \mathrm{~S}$ rDNA, PCR amplification (and sequencing) of insecticidal genes commonly harboured by this bacterium (e.g. cry, cyt and vip), analysis of their SDS-PAGE protein profiles and bioassays involving additional insect species should be also performed in order to complement the preliminary characterization of the isolated strains.

\section{Acknowledgements}

I thanks to the Consejo Nacional de Investigaciones Científicas y Técnicas (CONICET), Argentina (postdoctoral fellowship awarded to Dr. Leopoldo Palma). I also thanks to Dr. Diego Sauka for kindly providing HD1, HD133 and IPS82 Bt strains and to Alejandra Lutz for her help in insect rearing and providing larvae for preliminary bioassays. I thank to Dr. Eleodoro del Valle for his assistance in soil sampling and Dr. Laureano Frizzo for providing microbiological resources for performing bacterial isolation.

\section{References}

Ammons, D., et al., 2002. Usefulness of staining parasporal bodies when screening for Bacillus thuringiensis. Journal of Invertebrate Pathology. 79 203-204.
http://dx.doi.org/10.1016/S0022-2011(02)00018-6

de Maagd, R. A., et al., 2003. Structure, diversity, and evolution of protein toxins from spore-forming entomopathogenic bacteria. Annu Rev Genet. 37, 409-33. http://dx.doi.org/10.1146/annurev.genet.37.110801.143042

Donovan, W. P., et al., 2006. Discovery and characterization of Sip1A: a novel secreted protein from Bacillus thuringiensis with activity against coleopteran larvae. Appl Microbiol Biotechnol. 72, 713-719. http://dx.doi.org/10.1007/s00253-006-0332-7

Estruch, J. J., et al., 1996. Vip3A, a novel Bacillus thuringiensis vegetative insecticidal protein with a wide spectrum of activities against lepidopteran insects. Proc Natl Acad Sci USA. 93, 5389-5394. http://dx.doi.org/10.1073/pnas.93.11.5389

Ferré, J., Van Rie, J., 2002. Biochemistry and genetics of insect resistance to Bacillus thuringiensis. Annu Rev Entomol. 47, 501-33. http://dx.doi.org/10.1146/annurev.ento.47.091201.145234

Iriarte, J., et al., 1998. Environmental distribution and diversity of Bacillus thuringiensis in Spain. Syst Appl Microbiol. 21, 97-106. http://dx.doi.org/10.1016/S0723-2020(98)80012-X

Palma, L., et al., 2014. Bacillus thuringiensis toxins: an overview of their biocidal activity. Toxins (Basel). 6, 3296-325. http://dx.doi.org/10.3390/toxins6123296

Roh, J. Y., et al., 2007. Bacillus thuringiensis as a specific, safe, and effective tool for insect pest control. J Mol Biol. 17, 547-559.

Sanchis, V., 2011. From microbial sprays to insect-resistant transgenic plants: history of the biospesticide Bacillus thuringiensis. A review. Agron. Sustain. Dev. . 31, 217-231. http://dx.doi.org/10.1051/agro/2010027

Schnepf, E., et al., 1998. Bacillus thuringiensis and its pesticidal crystal proteins. Microbiol Mol Biol Rev. 62, 775-806.

Tabashnik, B. E., et al., 2009. Field-evolved insect resistance to Bt crops: definition, theory, and data. J Econ Entomol. 102, 2011-2025. http://dx.doi.org/10.1603/029.102.0601

van Frankenhuyzen, K., 2009. Insecticidal activity of Bacillus thuringiensis crystal proteins. J Invertebr Pathol. 101, 1-16. http://dx.doi.org/10.1016/j.jip.2009.02.009

Warren, G. W., et al., 1998. Auxiliary proteins for enhancing the insecticidal activity of pesticidal proteins. US patent 5770696.

$\mathrm{Wu}$, J., et al., 2007a. Adaptive evolution of cry Genes in Bacillus thuringiensis: implications for their specificity determination. Geno. Prot. Bioinfo. 5, 102-110. http://dx.doi.org/10.1016/S1672-0229(07)60020-5

Wu, J., et al., 2007b. Evidence for positive Darwinian selection of vip gene in Bacillus thuringiensis. J. Genet. Genomics. 34, 649-60. http://dx.doi.org/10.1016/S1673-8527(07)60074-5 